\title{
Comment on "Sub-anesthetic Xenon Increases Erythropoietin Levels in Humans: A Randomized Controlled Trial"
}

\author{
Anoop Balachandran ${ }^{1} \cdot$ David L. Streiner ${ }^{2,3} \cdot$ Joseph F. Signorile $^{1}$
}

Published online: 9 December 2016

(C) Springer International Publishing Switzerland 2016

Dear Editor,

This letter is in regard to the study titled "Sub-anesthetic Xenon Increases Erythropoietin Levels in Humans: A Randomized Controlled Trial" published recently in Sports Medicine [1]. This is the first study to look at an important question regarding the effects of xenon on circulating levels of erythropoietin (EPO) in healthy humans. As stated in the introduction of the paper, EPO has long been established as a potent performance enhancing substance [2]. As such, the study results could have considerable implications in the sports performance area.

The study randomly assigned 24 subjects to either xenon breathing or control gas breathing for $45 \mathrm{~min}$. The primary outcome measure was EPO levels in the blood. After 5 days of data collection, the study concluded that xenon increases EPO levels in humans, as evident in the title. However, the reported statistical analysis does not warrant this conclusion.

Although it is reported under "Statistical Analysis" that "single measurements were compared between the groups

A reply to this comment is available at doi:10.1007/s40279-016-0660-4.

This comment refers to the article available at doi:10.1007/s40279-016-0505-1.

Anoop Balachandran

a.balachandran@umiami.edu

1 Laboratory of Neuromuscular Research and Active Aging, University of Miami, Coral Gables, FL, USA

2 Department of Psychiatry and Behavioral Neurosciences, McMaster University, Hamilton, ON, USA

3 Department of Psychiatry, University of Toronto, Toronto, ON, USA at single time-points using Student's t test (two groups) in accordance with our statistician's advice," only withingroup or change from baseline score analysis is reported in the paper. Therefore, the conclusion of xenon being effective appears to be based on comparing a significant withingroup change observed in the xenon group to a non-significant change in the control group. Using simulated data, Bland and Altman have elegantly shown that the practice of comparing within-group $p$ values is conceptually wrong, invalid, and highly misleading [3]. If superiority is to be claimed in a trial, statistical tests that compare betweengroup mean differences should be conducted; that is, a group-by-time analysis of variance or a two-sample $t$ test.

In summary, the current conclusion of xenon increases EPO levels in humans is inappropriate and possibly misleading. We highly recommend authors conducting randomized controlled trials compare outcomes using between-group rather than within-group or tests against baseline methods.

\section{Compliance with Ethical Standards}

Anoop Balachandran, David Streiner, and Joseph Signorile declare that they have no conflict of interest relevant to the content of this letter. No financial support was received for the preparation of this letter.

\section{References}

1. Stoppe C, Ney J, Brenke M, et al. Sub-anesthetic xenon increases erythropoietin levels in humans: a randomized controlled trial. Sports Med. 2016;46(11):1753-66.

2. Momaya A, Fawal M, Estes R. Performance-enhancing substances in sports: a review of the literature. Sports Med. 2015;45(4):517-31.

3. Bland JM, Altman DG. Comparisons against baseline within randomised groups are often used and can be highly misleading. Trials. 2011;12:264-6215-12-264. 